\title{
Specific Leaf Weight and Nitrogen Allocation Responses to Light Exposure within Walnut Trees
}

\section{Klein', T.M. DeJong, S.A. Weinbaum, and T.T. Muraoka \\ Department of Pomology, University of California, Davis, CA 95616}

Additional index words. Juglans regia, photosynthetically active radiation, PAR, SLW, sunfleck, $\mathrm{N}$ partitioning

\begin{abstract}
Exposure to photosynthetically active radiation and the consequent effect on leaf mass per unit leaf area (SLW) and nitrogen (percent dry weight and $\mu \mathrm{g} \cdot \mathbf{m m}^{-2}$ ) allocation within tree canopies was investigated in walnut (Juglans regia 'Serr' and 'Hartley') trees. Percent contribution of discrete light flux densities below light saturation $\left(100-700 \mu \mathrm{mol} \cdot \mathrm{s}^{-1} \cdot \mathrm{m}^{-2}\right)$ to the total light exposure of individual spurs, exposed up to 9 hour $\cdot$ day $^{-1}$ to saturating light $\left(>700 \mu \mathrm{mol} \cdot \mathrm{s}^{-1} \cdot \mathrm{m}^{-2}\right)$, was minimal $(<1$ hour $)$, indicating that individual spurs were either exposed or shaded most of the day. SLW and $\mathbf{N}$ content per unit leaf area of individual spurs were highly correlated (secondorder polynomial curve fit) with light exposure within the tree canopy, indicating uneven allocation of available $\mathbf{N}$ for optimal utilization. Nitrogen expressed as percent dry weight was not correlated with light exposure and SLW. Leaf $N$ content per leaf area was highly correlated (linear fit) with SLW.
\end{abstract}

Productivity of plants depends on net photosynthesis, which, in turn, may be limited by light, among other factors. Numerous laboratory studies have evaluated the photosynthetic response curves to light. Light saturation of walnut is approached at photosynthetic photon fluxes of 600 to 800 $\mu \mathrm{mol} \cdot \mathrm{s}^{-1} \cdot \mathrm{m}^{-2}$ (Tombesi et al., 1983) and that of cherry, peach, and plum at 400 to $700 \mu \mathrm{mol} \cdot \mathrm{s}^{-1} \cdot \mathrm{m}^{-2}$ (DeJong, 1983) and pecan requires $675 \mu \mathrm{mol} \cdot \mathrm{s}^{-1} \cdot \mathrm{m}^{-2}$ (Crews et al., 1980) for light saturation of photosynthesis.

In the orchard, net photosynthesis may be limited by various factors besides light, i.e., temperature, $\mathrm{CO}_{2}$ concentration, and water deficit (reduced stomatal conductance). Nevertheless, as a result of excessive vegetative growth, light may limit individual leaf photosynthesis in commercial orchards. In practice, light measurements are not taken routinely and researchers generally assume that light exposure is variable within the tree canopy, where photosynthesis proceeds, analogous to laboratory studies, at nonsaturating light intensities. Many walnut orchards in California are extremely shaded as a result of complete canopy closure. We aimed to evaluate light fluxes within these dense canopies and the consequent effects on specific leaf weight and $\mathrm{N}$ allocation among leaves within the trees. Specific leaf weight and leaf $\mathrm{N}$ expressed on an area basis have been related to light, exposure in other fruit trees (Avery, 1977; Barden, 1974, 1977, 1978;

Received for "publication 23 Apr. 1990. We are grateful to T. Kaputska and R.M. Carlson for help with nitrogen analysis. The cost of publishing this paper was defrayed in part by the payment of page charges. Under postal regulations, this paper therefore must be hereby marked advertisement solely to indicate this fact.

'On sabbatical from the Inst. of Horticulture, ARO, The Volcani Center, Bet Dagan 50250, Israel.
Crips, 1972; DeJong, 1982; DeJong and Doyle, 1985; DeJong et al., 1989; Jackson and Palmer, 1977; Kappel and Flore, 1983; Marini and Marini, 1983; MacMillen and 'McClendon, 1983; Weinbaum et al., 1989).. Quantitative evaluation of this relationship should be helpful in formulating management practices (i.e., pruning and $\mathrm{N}$ nutrition) for walnuts.

The orchard. Five individual-tree replicates of 'Serr' and 'Hartley' Persian walnut trees, grafted on black walnut (Juglans hind-
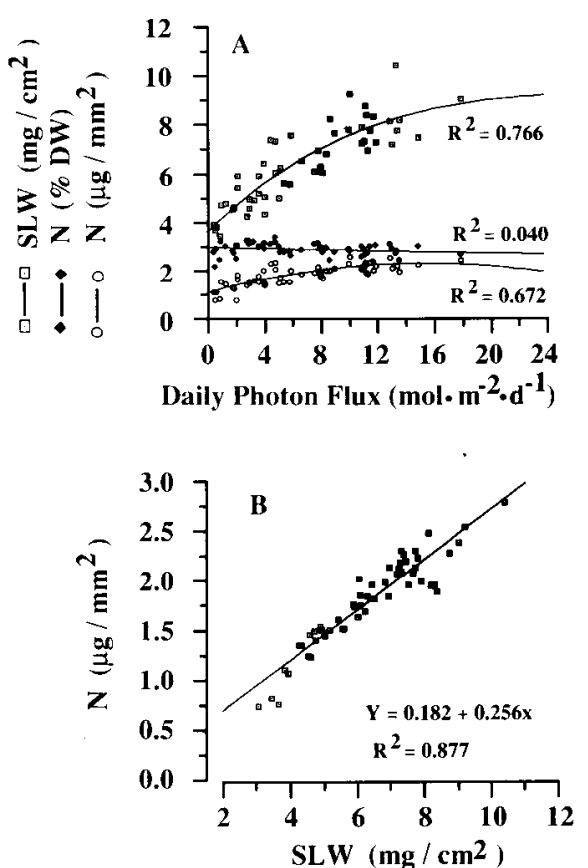

Fig. 1. Relationship (A) between daily PAR measured above 'Hartley' walnut spurs and the specific leaf weight (SLW) and $\mathrm{N}$ of spur leaves expressed on a dry-weight (DW) and area basis; (B) between SLW and N (area basis). sii) rootstock, were selected for measurements in a commercial orchard near Winters, Calif. Trees were 16 years old and planted $8.5 \times 8.5 \mathrm{~m}$, with cultivar rows oriented east-west. Tree height was 8 to $10 \mathrm{~m}$, with the canopies closed near the top. The trees were only lightly pruned for 3 years before the study and not pruned at all in the year of the study.

Light measurements. Transmittance of photosynthetic photon flux (PPF, 400--700 $\mathrm{nm})$ and sunfleck measurements under tree canopies were taken on 15 July 1989 with an 80-cm 80 sensor Light Ceptometer (model SF-80; Decagon Devices, Pullman, Wash.). The ceptometer can be used to measure PPF and to take sunfleck readings simultaneously. Percent photosynthetically active radiation (PAR) transmittance was calculated as the ratio of below to above canopy irradiance. Above-canopy irradiance was measured in an open field. Below-canopy irradiance varied and, therefore, readings were averaged from measurements taken in three positions along tree rows: a) walking on both sides of trunks, along tree rows (one reading each step, 20 readings per tree, averaged), and in a circle; $b$ ) around tree trunks; and c) between tree trunks. With positions $\mathrm{b}$ and $\mathrm{c}$, one reading was taken every $45^{\circ}$ (eight readings per circle, averaged for each position). Only relative values of the sunfleck readings could be measured using a manual threshold setting because of the extreme shade under the canopy. The manual light threshold for shade was set in a shed under homogeneous light exposure of $17 \mu \mathrm{mol} \cdot \mathrm{s}^{-1} \cdot \mathrm{m}^{-2} \mathrm{PAR}$.

Measurements of PAR above individual spurs were carried out under clear skies in 1989 following canopy closure (6-25 June
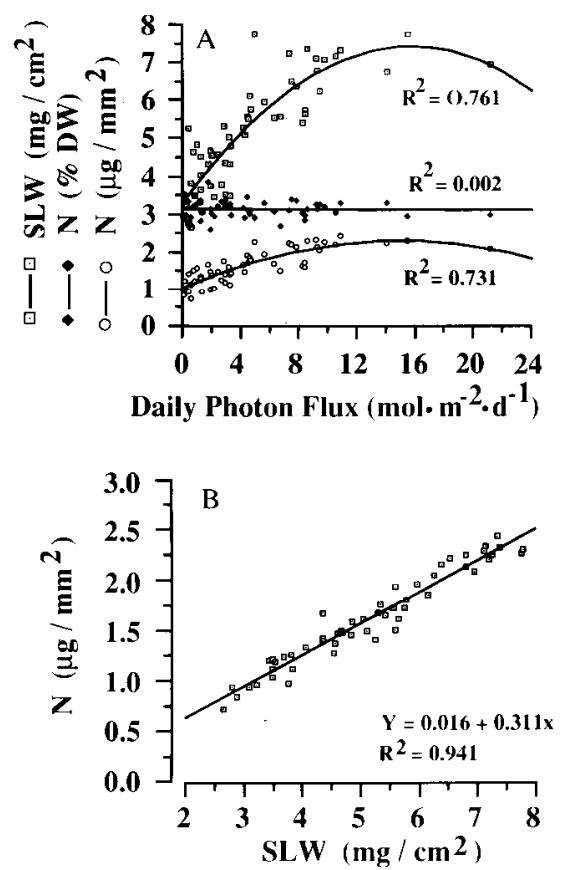

Fig. 2. Relationship (A) between daily PAR measured above 'Serr' walnut spurs and the specific leaf weight (SLW) and $\mathrm{N}$ of spur leaves expressed on a dry-weight (DW) and area basis; (B) between SLW and N (area basis). 


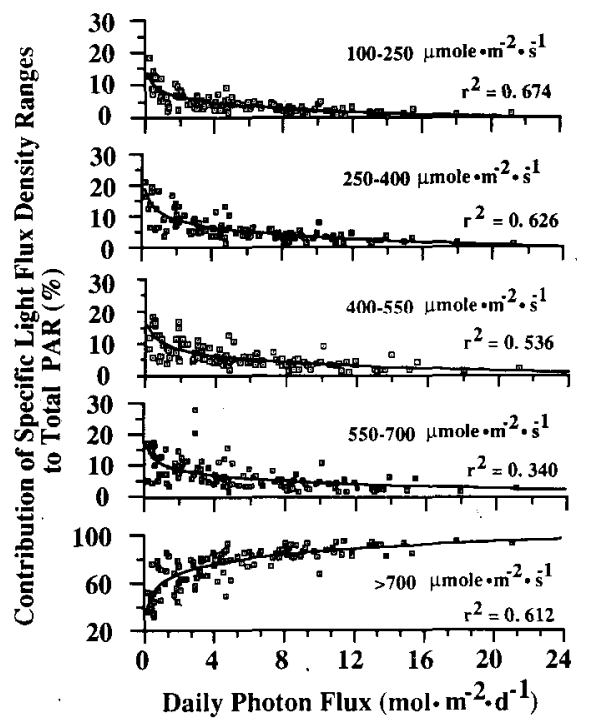

Fig. 3. Percent contribution of specific light flux ranges to total daily PAR measured above walnut spurs during 6 June-8 July 1989 near Winters, Calif. Log line equations were: $\mathrm{y}=8.2$ - $6.1 \log (\mathrm{x}), \mathrm{y}=11.3-8.1 \log (\mathrm{x}), \mathrm{y}=$ $9.9-6.4 \log (\mathrm{x}), \mathrm{y}=10.9-6.2 \log (\mathrm{x})$, and $\mathrm{y}=59.9+26.7 \log (\mathrm{x})$ for $100-250$, 250-400, 400-550, 550-700, and >700 $\mu \mathrm{mol} \cdot \mathrm{s}^{-1} \cdot \mathrm{m}^{-2}$, respectively.

and 26 June to 8 July in 'Serr' and 'Hartley', respectively). Irradiance was measured around and within the canopies of three to four trees, at a total of 55 positions for each cultivar, according to DeJong and Doyle (1985). Two battery-operated data loggers (CR21 micrologger; Campbell Scientific, Logan, Utah), each with seven quantum sensors, were used. Sensors were individually calibrated with a quantum sensor (LI-1905; LI-COR, Lincoln, Neb.) and positioned horizontally. immediately above individual spurs. The data loggers were programmed to scan each sensor once every $10 \mathrm{sec}$ and to $\log$ the data as an average over 4-h intervals. The logged data consisted of the fraction of time that the sensors were exposed to light of $<100,250$ $400,400-550,550-700$, and $>700$ $\mu \mathrm{mol} \cdot \mathrm{s}^{-1} \cdot \mathrm{m}^{-2}$. Sensors were left in position for 24 to $48 \mathrm{~h}$, and- the irradiance per day was calculated and expressed as exposure time (h) and photon flux (mol.day ${ }^{-1} \cdot \mathrm{m}^{-2}=$ product of the exposure times multiplied by the median value of the various photon fluxes). Irradiance below $100 \mu \mathrm{mol} \cdot \mathrm{s}^{-1} \cdot \mathrm{m}^{-2}$ was disregarded because of high variance of readings at very low photon fluxes. Light compensation point in walnuts is $\approx 50$ $\mu \mathrm{mol} \cdot \mathrm{s}^{-1} \cdot \mathrm{m}^{-2}$ (Tombesi et al., 1983). The error introduced, therefore, by neglecting readings below $100 \mu \mathrm{mol} \cdot \mathrm{s}^{-1} \cdot \mathrm{m}^{-2}$ was considered to be minor. Irradiance above 700 $\mu \mathrm{mol} \cdot \mathrm{s}^{-1} \cdot \mathrm{m}^{-1}$ was weighted as 700 $\mu \mathrm{mol} \cdot \mathrm{s}^{-1} \cdot \mathrm{m}^{-2}$ because leaf photosynthesis in walnut is saturated above this level (Tombesi et al., 1983).

Leaflet sampling and analysis. Leaflets were sampled immediately after irradiance measurements were completed on each spur. Leaf areas were measured with a Delta T area meter (Decagon, Seattle, Wash.), then
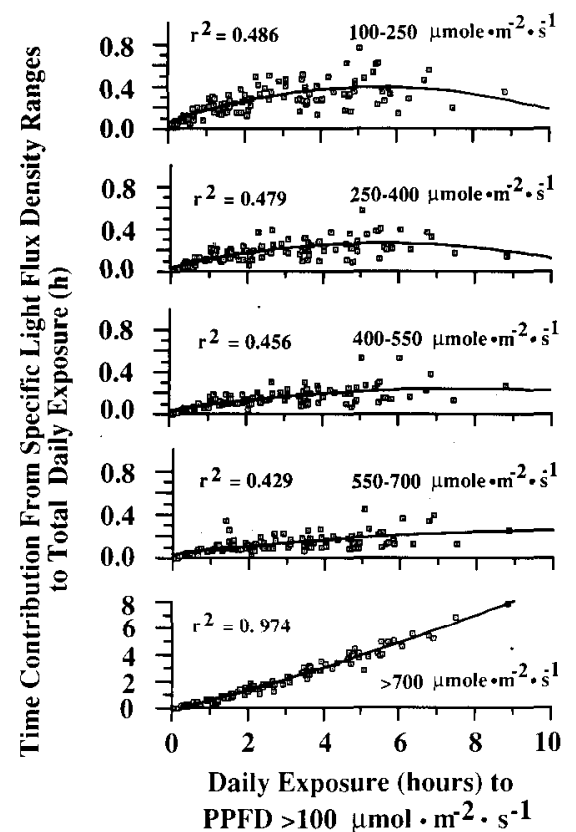

Fig. 4. Time (h) contribution of specific light flux ranges to total daily exposure (hours) of walnut spurs to PAR $>100 \mu \mathrm{mol} \cdot \mathrm{s}^{-1} \cdot \mathrm{m}^{-2}$ during 6 June-8 July 1989 near Winters, Calif. Second-order polynomial line equations were: $y=0.06+0.12 x-0.02 x^{2}, y=0.04+$ $0.08 \mathrm{x}-0.01 \mathrm{x}^{2}, \mathrm{y}=0.03+0.05 \mathrm{x}-0.004 \mathrm{x}^{2}$ $\mathrm{y}=0.03+0.04 \mathrm{x}-0.002 \mathrm{x}^{2}$, and $\mathrm{y}=0.19$ $+0.70 \mathrm{x}+0.02 \mathrm{x}^{2}$ for $100-250,250-400,400-$ $550,550-700$, and $>700 \mu \mathrm{mol} \cdot \mathrm{s}^{-1} \cdot \mathrm{m}^{-2}$, respectively.

washed, dried at $55 \mathrm{C}$, and ground to pass a 30-mesh screen. Digestion of leaf samples and conductimetric determination of $\mathrm{N}$ were carried out according to Carlson (1978). Averages and SE values of sunfleck and PPF values were calculated from measurements of five individual trees of each cultivar. Linear and polynomial curves for data in Figs. 1 through 4 were fitted from the light measurements taken above 55 individual spurs of each cultivar and their corresponding SLW and $\mathrm{N}$ analyses.

Sunfleck measurements showed $\approx 1.6$ times more sunlight penetrating the 'Hartley' than the 'Serr' canopies during the morning hours of 15 July (Table 1). At noon, maximum percent light transmittance of PAR under the 'Hartley' and 'Serr' canopies was $5.7 \% \pm$ $1.0 \%$ and $2.0 \% \pm 0.1 \%$, respectively. Ratios of PPF at $0930 \mathrm{HR}$ and $1315 \mathrm{HR}$, between the two cultivars, were similar to ratios of the sunfleck measurement. At 1145 HR, however, PPF under 'Hartley' was 2.85 times greater than under 'Serr', probably a result of reflected radiation. Sunfleck measurements indicate the percentage of ground exposed to sun penetrating the canopy, while PPF measurements integrate reflected radiation as well. Canopy closure of the two cultivars in the orchard had occurred 4 to 6 weeks before the measurements in Table 1 were taken. These measurements, therefore, reflect the prevailing light conditions under closed-canopy walnut orchards and the magnitude of differences between two distinct cultivars. These differences in canopy light characteristics may occur because 'Serr' is a more vigorous cultivar, with a different tree and leaf morphology, resulting in a denser and slightly more shaded canopy than 'Hartley'.

Nitrogen content and SLW of individual spur leaves were correlated with the total daily light exposures measured immediately above the spur. Measurements were taken soon after the canopy was fully developed, and the specific leaf weight of the spur leaves was established (S.A.W., unpublished data). SLW and micrograms $\mathrm{N} / \mathrm{mm}^{2}$ were significantly correlated with total daily light exposure (Figs. 1 and 2); second-order polynomial correlations $\left(r^{2}\right)$ characterized SLW and $\mathrm{N}$ for both cultivars. Linear correlations (rather than polynomial) with similar $r^{2}$ values could be fitted to the data relating SLW and N to PPF, but the data deviated from the curve fit at the low end of the curve. Leaf $\mathrm{N}$, as percent dry weight $(\% \mathrm{DW})$, was not correlated with light exposure. SLW and N (area basis) were linearly correlated (Figs. 1 and 2). The high correlations $(\approx 0.9)$ indicate a very strong relationship, when taking into account a $10 \%$ analytical error in $\mathrm{N}$ determination.

Light was measured above the spur, while SLW and $\mathrm{N}$ were measured on several leaflets below, shading each other to some extent. The correlations between light measurements and SLW and N (area basis) probably would have been even higher if they had been made for individual leaflets and for extended periods. The SLW value may reflect an integrated value of the incident light better than light sensors positioned above spurs could measure.

Light exposure time measurements were logged at 4-h intervals and at five specific light flux ranges that contribute to daily photosynthesis. The results were calculated and expressed as percent energy contribution (daily photon flux, Fig. 3), based on daily exposure hours (Fig. 4) to specific light flux ranges. Both expressions are presented, since either a short exposure (contribution) time at high light fluxes or a long exposure (contribution) time at low light fluxes can (theoretically) contribute significantly to daily photosynthesis.

In extreme shade, $\approx 60 \%$ of the intercepted PAR energy came. from light fluxes of 100 to $700 \mu \mathrm{mol} \cdot \mathrm{s}^{-1} \cdot \mathrm{m}^{-2}$ distributed evenly within this range (Fig. 3). The percent contribution of specific light flux ranges below saturation decreased exponentially as the total daily light interception increased. However, when incident PPF was expressed as exposure time to various light flux ranges, it became apparent that the combined contribution of 100 to $700 \mu \mathrm{mol} \cdot \mathrm{s}^{-1} \cdot \mathrm{m}^{-2}$ was $\approx 1$ $\mathrm{h} \cdot \mathrm{day}^{-1}$ at most (Fig. 4). The rest of the time the spur was in darkness (at night) or at $<100$ $\mu \mathrm{mol} \cdot \mathrm{s}^{-1} \cdot \mathrm{m}^{-2}$. Furthermore, the 100 to 700 $\mu \mathrm{mol} \cdot \mathrm{s}^{-1} \cdot \mathrm{m}^{-2}$ contribution was minimal for shaded spurs. The percent contribution to daily light exposure of light fluxes between light compensation and light saturation were, therefore, greater in shaded than in exposed leaves, but the absolute exposure time to these intermediate light fluxes was minimal. Ap- 
Table 1. Relative sunfleck (SF) measurement and transmittance of photosynthetically active radiation (PAR) under the canopies of 'Serr' and 'Hartley' walnut trees on 15 July 1989 in Winters, Calif.'

\begin{tabular}{|c|c|c|c|c|}
\hline \multirow{2}{*}{$\begin{array}{l}\text { Time } \\
\text { (HR) }\end{array}$} & \multirow{2}{*}{$\begin{array}{l}\text { Relative SF } \\
\text { Hartley/Serr }\end{array}$} & \multicolumn{3}{|c|}{$\operatorname{PAR}(\%)$} \\
\hline & & Hartley & Serr & Hartley/Serr \\
\hline 0930 & 1.63 & $1.9 \pm 0.0$ & $1.2 \pm 0.2$ & 1.58 \\
\hline 1145 & 1.66 & $5.7 \pm 1.0$ & $2.0 \pm 0.1$ & 2.85 \\
\hline 1315 & 1.33 & $2.7 \pm 0.5$ & $2.2 \pm 0.2$ & 1.23 \\
\hline
\end{tabular}

${ }^{2}$ Means and SE of three types of measurements (around trunks and between canopies along tree rows, and walking on two sides of trees along tree rows).

parently, spurs usually were either exposed to saturation levels of light or extremely shaded. Exposure to levels between photosynthetic light saturation and compensation was minimal. Such a light regime in the canopy is the result of a very effective filtering mechanism', whereby the outer layer of leaves of the canopy can effectively block light transmittance. Similar results were reported by Heinicke (1966) for an apple canopy where only extreme high- and low-light zones were found, with correspondingly high and low rates of net $\mathrm{CO}_{2}$ assimilations.

It has been argued that adaptation to high photosynthetic efficiency under low-light fluxes is important for the overall performance of a crop under field conditions, since the majority of photosynthesis in the field occurs at nonsaturating light fluxes (Ort and Baker, 1988). Our data from walnut indicate that the premise of the above argument may not be valid in fruit trees not only on an orchard basis, where planting densities limit the exposure of the outer canopy, but also on an individual-tree basis, since leaves are either highly exposed (exterior of canopy) or highly shaded (canopy interior) most of the day. Within the canopy of a shaded walnut tree, there are many spurs exposed daily, soon after canopy closure, to PPF of $>100$ $\mu \mathrm{mol} \cdot \mathrm{s}^{-1} \cdot \mathrm{m}^{-2}$ only for a short. time. These spurs, which are characterized by a very low SLW $\left(2-3 \mathrm{mg} \cdot \mathrm{cm}^{-2}\right)$ and- low $\mathrm{N}(\approx 1$ $\mu \mathrm{g} \cdot \mathrm{mm}^{-2}$ or less), are capable of survival, either on their own or by using carbohydrate resources from the more exposed parts of the tree. The photosynthetic characteristics of shade and sun leaves differ (Bjorkman and Holmgren, 1963; Charles-Edwards et al., 1974) and even completely defoliated shoots can support fruit growth by importing car- bohydrates from adjacent shoots (Hailer and Magness, 1933). However, mature leaves are not thought to be net importers of carbon (Turgeon, 1989). More research is needed to understand the carbon economy of mature leaves in these very shaded tree canopies.

\section{Literature Cited}

Avery, D.J. 1977. Maximum photosynthetic rateA case study in apple. New Phytol. 78:55-63.

Barden, J.A. 1974. Net photosynthesis, dark respiration, specific leaf weight, and growth of J. Amer. Soc. Hort. Sci. 99:547-551.

Barden, J.A. 1977. Apple tree growth, net photosynthesis, dark respiration, and specific light weight as affected by continuous and intermittent shade. J. Amer. Soc. Hort. Sci. 102:391394

Barden, J.A. 1978. Apple leaves, their morphology and photosynthetic potential. HortScience 13:644-646.

Bjorkman, O. and P. Holmgren. 1963. Adaptability of the photosynthetic apparatus to light intensity in ecotypes from exposed and shaded habitats. Physiol. Plant. 16:899-914.

Carlson, R.M. 1978. Automated separation and conductimetric determination of ammonia and dissolved carbon dioxide. Anal. Chem. 50:15281531.

Charles-Edwards, D. A., J. Charles-Edwards, and F.I. Sant. 1974. Leaf photosynthetic activity in six temperate grass varieties grown in contrasting light and temperature environments. J. Expt. Bot. 25:715-724.

Crews, C.E., R.E. Worley, J.P. Syvertsen, and M.G. Bausher. 1980. Carboxylase activity and seasonal changes in $\mathrm{CO}_{2}$ assimilation rates in three cultivars of pecan. J. Amer. Soc. Hort. Sci. 105:798-801.

Crips, J.E.L. 1972. The effect of shading and Alar application on apple root: shoot ratio in Western Australia. J. Hort. Sci. 47:291-299.

DeJong, T.M. 1982. Leaf nitrogen content and young apple trees as influenced by light regime.
$\mathrm{CO}_{2}$ assimilation capacity in peach. J. Amer. Soc. Hort. Sci. 107:955-959.

DeJong, T.M. 1983. $\mathrm{CO}_{2}$ assimilation characteristic of five Prunus tree fruit species. J. Amer. Soc. Hort. Sci. 108:303-307.

DeJong, T.M. and F. Doyle. 1985. Seasonal relationship between leaf nitrogen content (photosynthetic capacity) and leaf canopy ligh exposure in peach (Prunus persica). Plant Cell \& Environ. 8:701-706.

DeJong, T.M., K.R. Day, and R.S. Johnson. 1989. Partitioning leaf nitrogen with respect to within canopy light exposure and nitrogen availability in peach (Prunis persica). Trees 3:89-95.

Hailer, M.H. and J.R. Magness. 1933. Relation of leaf area and position to quality of fruit and to fruit bud differentiation in apples. U.S. Dept. Agr. Tech. Bul. 338.

Heinicke, D.R. 1966. The effect of natural shade on photosynthesis and light intensity in Red Delicious apple trees. Proc. Amer. Soc. Hort. Sci. $88: 1-8$.

Jackson, J.E. and J.W. Palmer. 1977. Effects of shade on the growth and cropping of apple trees. 1. Experimental details and effects on vegetative growth. J. Hort. Sci. 52:245-252.

Kappel, F. and J.A. Flore. 1983. Effect of shade on photosynthesis, specific leaf weight, leaf chlorophyll content, and morphology of young peach trees. J. Amer. Soc. Hort. Sci. 108:541544.

MacMillen, G.G. and J.H. McClendon. 1983. Dependence of photosynthetic rates on leaf density thickness in deciduous woody plants grown in sun and shade. Plant Physiol. 72:674-678.

Marini, R.P. and M.C. Marini. 1983. Seasonal changes in specific leaf weight net photosynthesis and chlorophyll content of peach leaves as affected by light penetration and canopy position. J. Amer. Soc. Hort. Sci. 108:600-605.

Ort, D.R. and N.R. Baker. 1988. Consideration of photosynthetic efficiency at low light as a major determinant of crop photosynthetic performance. Plant Physiol. Biochem. 26:555-565.

Tombesi, A., T.M. DeJong, and K. Ryugo. 1983. Net $\mathrm{CO}_{2}$ assimilation characteristics of walnut leaves under field and laboratory conditions. J. Amer. Soc. Hort. Sci. 108:558-561.

Turgeon, R. 1989. The sink-source transition in leaves. Annu. Rev. Plant Physiol. Plant Molec. Biol. 40:119-138

Weinbaum, S.A., S.M. Southwick, K.A. Shackel, T.T. Muraoka, W. Krueger, and J.T. Yeager. 1989. Photosynthetic photon flux influences macroelement weight and leaf dry weight per unit of leaf area in prune tree canopies. J. Amer. Soc. Hort. Sci. 114:720-723. 